\title{
Advanced automated emergency control strategy for embedded VSC-HVDC links
}

\author{
S. Polster(D, H. Renner, K. Friedl, O. Samuelsson
}

\begin{abstract}
This paper proposes an advanced emergency control strategy for embedded VSC-HVDC links after AC disturbances, such as line tripping and generation loss. The control goals are to minimize the impact of the disturbance on the AC-network, which includes improving the long-term voltage stability with utilizing possible unloading capacity of parallel AC elements. The proposed algorithm is evaluated against other control strategies for embedded VSC-HVDC links by applying it to a simple demonstration network. The test system includes all necessary VSC converter dynamics, the VSC-HVDC link current and voltage limits and simple load recovery characteristics for an evaluation of the long term voltage stability. The simulation results are explained and the advantages of the proposed emergency control strategy are discussed.
\end{abstract}

Keywords: VSC-HVDC links; long term voltage stability; cascading line tripping; emergency control scheme

\section{Erweitertes automatisches Notfallregelkonzept für eingebettete VSC-HVDC-Leitungen.}

In dieser Arbeit wird ein erweitertes Regelkonzept für eingebettete VSC-HVDC-Leitungen mit dem Fokus auf die Stützung des parallelen AC-Systems nach Störungen wie Leitungs- und Generatorausfällen vorgestellt. Die Betriebsziele der Regelung bestehen einerseits darin, die direkten Auswirkungen der Störung auf das AC-System zu minimieren, und andererseits in der Sicherstellung einer langfristigen Spannungsstabilität. Das vorgestellte Regelkonzept wird in einem Testsystem mit einfacher Netztopologie angewandt und seine Effektivität mit der von bereits vorhandenen Regelstrategien verglichen. Im Testsystem sind das erforderliche dynamische Verhalten der VSC-Umrichter, die Betriebsgrenzen der VSC-HVDC-Leitung sowie ein für Spannungsstabilitätsbetrachtungen geeignetes dynamisches Lastverhalten implementiert. Die Simulationsergebnisse werden hinsichtlich der Funktionsweise und der sich daraus ergebenden Vorteile des vorgestellten Regelkonzeptes erläutert.

Schlüsse/wörter: VSC-HVDC-Leitungen; Langzeitspannungsstabilität; kaskadierende Leitungsausfälle; Notfallregelkonzept

Received June 29, 2020, accepted September 18, 2020, published online October 15, 2020

(c) The Author(s) 2020

\section{Introduction}

The combination of increasing energy consumption, changes in local distribution of generation centers and a rather slow grid expansion has led to an increased loading of the AC transmission system with higher risk of major disturbances and blackouts. When they occur, the main causes are cascading tripping of lines $[1,2]$ and voltage collapses $[3,4]$. The therefore resulting time frame for an emergency control action has to span a range from seconds - for short term voltage instability and cascaded line tripping involving distance relays and fast overcurrent relays - up to several minutes - for long term voltage stability and overload protection relays $[5,6]$.

Embedded VSC-HVDC links, with several projects to be commissioned in the near future or already in operation, e.g. the Swedish SouthWest Link, the French-Spanish interconnection between Perpignan and Figueres or the Trans Bay Cable between San Francisco and Pittsburg, offer additional flexibility for emergency control actions. Due to the ability of a fast and independent active and reactive power control, they can be used to address stability issues concerning power oscillations, short and long term voltage instability and cascaded line tripping. A use case has been already examined to improve the long term voltage stability of the Nordic32Bus system [7].

This paper is organized as follows. In Sect. 2 a review on basic control strategies for embedded VSC-HVDC links and their influence on steady state loadability and AC line loading is given. The proposed emergency control strategy is introduced in Sect. 3 and is evaluated in Sect. 4 using a small demonstration network. The conclusions are made in Sect. 5 .

\section{Review on PQ-control strategies of embedded VSC-HVDC} links

The steady state operation point of the parallel AC lines is affected by the active and reactive power set points of the terminal converters of the VSC-HVDC link. The VSC-HVDC link offers a flexible possibility to control the load flow in the AC network, due the independent control of active and reactive power. The simplest topology for an embedded VSC-HVDC link is shown in Fig. 1.

As shown in [8], the maximum loading capacity of the system consisting of $A C$ and $D C$ connection in parallel is reached, if the active power of the converter supplying power to the $A C$ grid is set according to

$$
p_{D C}=i_{\text {Conv }, \max } \cdot v_{\text {Conv }, A C} \cdot \sin \left(\delta_{1}-\delta_{2}\right)
$$

Stefan Polster is a recipient of a DOC Fellowship of the Austrian Academy of Sciences at the Institute of Electrical Power Systems, TU Graz.

Polster, Stefan, IEAN, Graz University of Technology, Graz, Austria (E-mail: stefan.polster@tugraz.at); Renner, Herwig, IEAN, Graz University of Technology, Graz, Austria; Friedl, Katrin, IEAN, Graz University of Technology, Graz, Austria; Samuelsson, Olof, IEA, Lund University, Lund, Sweden 


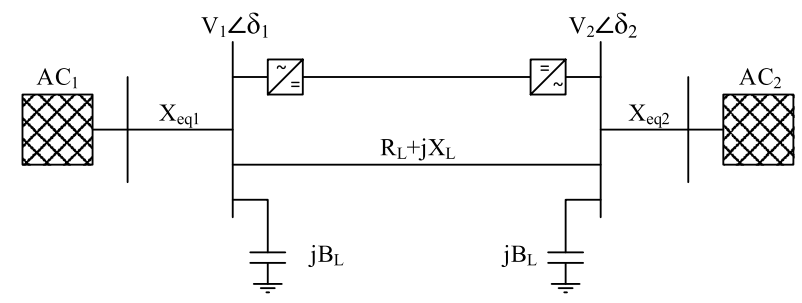

Fig. 1. Parallel $D C / A C$ connection of two $A C$ networks

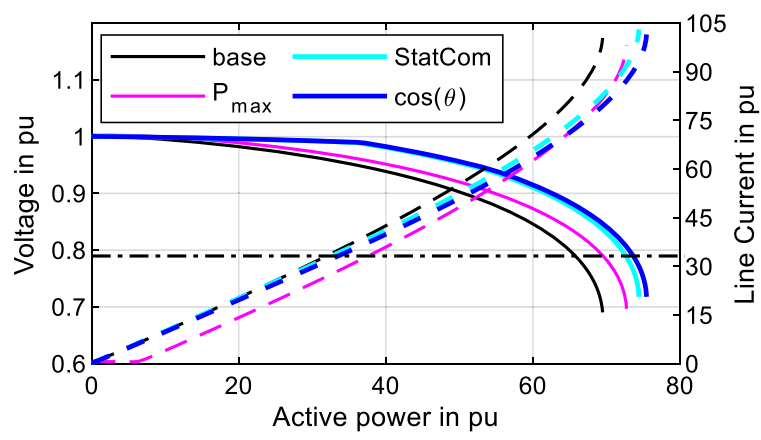

Fig. 2. PV curves and line current for different control strategies and base case without HVDC Link. The solid lines are the voltages of the load bus, the dashed lines are the overall currents of the parallel AC lines and the dash-dotted line is the AC current limit (Colour figure online)

The remaining capacity of the converter is utilized to control the $\mathrm{AC}$-voltage of the terminal with a maximum reactive power of

$$
q_{D C}=i_{\text {conv, } \max } \cdot v_{\text {conv, } A C} \cdot \cos \left(\delta_{1}-\delta_{2}\right)
$$

In the following the term base is used to describe the scenario without VSC-HVDC link. The term $P_{\max }$-control is used, if the whole capacity of the VSC-HVDC link converters is utilized to transport active power. StatCom-control refers to operation of the VSC-HVDC link in $A C$ voltage control on both terminals without any active power transfer. If the active and reactive power is set according to equations (1) and (2), the term $\cos (\theta)$-control is used.

Besides maximizing the loading capacity respectively, the long term voltage stability of the embedded system, a certain unloading of the $\mathrm{AC}$ lines is a desirable control goal for a stressed system to keep $(N-x)$-security. Depending on the actual terminal voltage, the most effective unloading is achieved by $P_{\max }$-control at closeto-nominal voltage levels and $\cos (\theta)$-control at higher voltage differences between the terminals. The reason for this is the voltage difference causing reactive power transfer on the AC line.

The effects of the three mentioned control strategies on loading capacity and the AC-line currents are demonstrated in the following based on a steady state simulation of the topology depicted in Fig. 1. The AC1-network is acting as a slack node, the AC2network as a simple active power load without any voltage control. The $\mathrm{AC}$ system parameters in pu are $x_{\mathrm{eq} 1}=0.0014, x_{\mathrm{eq} 2}=0.0007$, $r_{\mathrm{L}}=0.0006, x_{\mathrm{L}}=0.0046, b_{\mathrm{L}}=0.0783$, with base values $S_{B}=100$ MVA and $V_{B}=380 \mathrm{kV}$. The thermal current limit of the $A C$ line is 33.2. The rated power of the VSC-HVDC link is $6 \mathrm{pu}$.

The results summarized in Fig. 2 and Table 1 show clearly the advantage of $P_{\max }$-control in terms of $\mathrm{AC}$ unloading and of $\cos (\theta)$ control in terms of maximal loading capacity. The stated effectiveness based on the rated power of the VSC-HVDC link is depending on the actual $A C$ network. The efficiency is the ratio of the change in
Table 1. Active load power corresponding to voltage stability and line current limits

\begin{tabular}{lllll}
\hline $\begin{array}{l}\text { Control } \\
\text { strategy }\end{array}$ & $\begin{array}{l}\text { Active load } \\
\text { power, } \\
\text { stability limit } \\
\text { reached }\end{array}$ & $\begin{array}{l}\text { Active load } \\
\text { power, } \\
\text { current limit } \\
\text { reached }\end{array}$ & $\begin{array}{l}\text { Efficiency } \\
\text { increasing } \\
\text { the current } \\
\text { limit }\end{array}$ & $\begin{array}{l}\text { Efficiency } \\
\text { increasing } \\
\text { the voltage } \\
\text { stability }\end{array}$ \\
\hline Base case & 69,31 & 31,83 & - & - \\
$P_{\max }$ & 72,56 & 37,49 & 0,94 & 0,54 \\
StatCom & 74,24 & 32,59 & 0,13 & 0,82 \\
$\cos (\theta)$ & 75,27 & 33,51 & 0,28 & 0,99 \\
\hline
\end{tabular}

load power before the limitation is reached and the rated converter power.

\section{Introduction of advanced emergency control strategy}

The goal of the proposed automated emergency control strategy (ECS) is to increase the loading capacity and to limit the effects of a disturbance on the remaining $A C$ system. Remembering the results of the simple example from Sect. 2, a practical approach to this goal is to combine the $P_{\max }$ - and $\cos (\theta)$-controls, whereby a smooth transition between them has to be enabled based on measurable quantities. The obvious choice is the magnitude of the terminal voltage of the converter, $v_{P C C}$. The gradual transition starts if $v_{P C C}$ drops under an upper voltage limit $v_{\text {trans, up }}$ and is finished if $V_{P C C}$ reaches a lower voltage limit $v_{\text {trans, low }}$.

Consequently, the ECS has a voltage depending control behavior, which can be split into operation schemes:

1) $P_{\text {prior }}$-scheme ( $\left.v_{P C C} \geq v_{\text {trans, up }}\right)$

In this operation scheme the target is to avoid overloading remaining $\mathrm{AC}$ lines after a line trip and in the allocation of converter capacity active power has priority. A Pl-controller is keeping the node voltage angle difference between the converter terminals at precontingency value and is providing the set-point for the active power of the VSC-HVDC link. Remaining converter capacity is used to control the voltage at the terminal.

2) Transition phase $\left(v_{\text {trans, up }}>v_{P C C}>v_{\text {trans, low }}\right)$

With decreasing voltage magnitudes, the AC loading becomes more dependent on the reactive power and the maximum loading capacity becomes an additional issue. As a reaction to that, the active power limit of the controller is gradually reduced to the value stated in equation (1). Thus, the voltage controller can utilize more converter capacity.

3) $\cos (\theta)$-scheme $\left(v_{P C C} \leq v_{\text {trans, low }}\right)$

If the voltage at the PCC drops below the lower voltage limit for the transition phase, the priority has to be fully set on the maximization of the loading capacity of the system. Therefore, the active and reactive powers are set to the values given by the equations (1) and (2).

The inclination of the limit curve $k_{\text {trans }}$ is introduced to implement this operation behavior in the control loop of a converter. $k_{\text {trans }}$ calculates as follows and is limited to values between 0 and 1. Inherent to the limitation $k_{\text {trans }}$ is constant 1 for $v_{P C C} \geq v_{\text {trans, up }}$ and constant 0 for $v_{P C C} \leq v_{\text {trans, }}$ low

$$
k_{\text {trans }}=\frac{v_{\text {pcc }}-v_{\text {trans,low }}}{v_{\text {trans, up }}-v_{\text {trans,low }}}, \quad k_{\text {trans }} \in[0,1]
$$




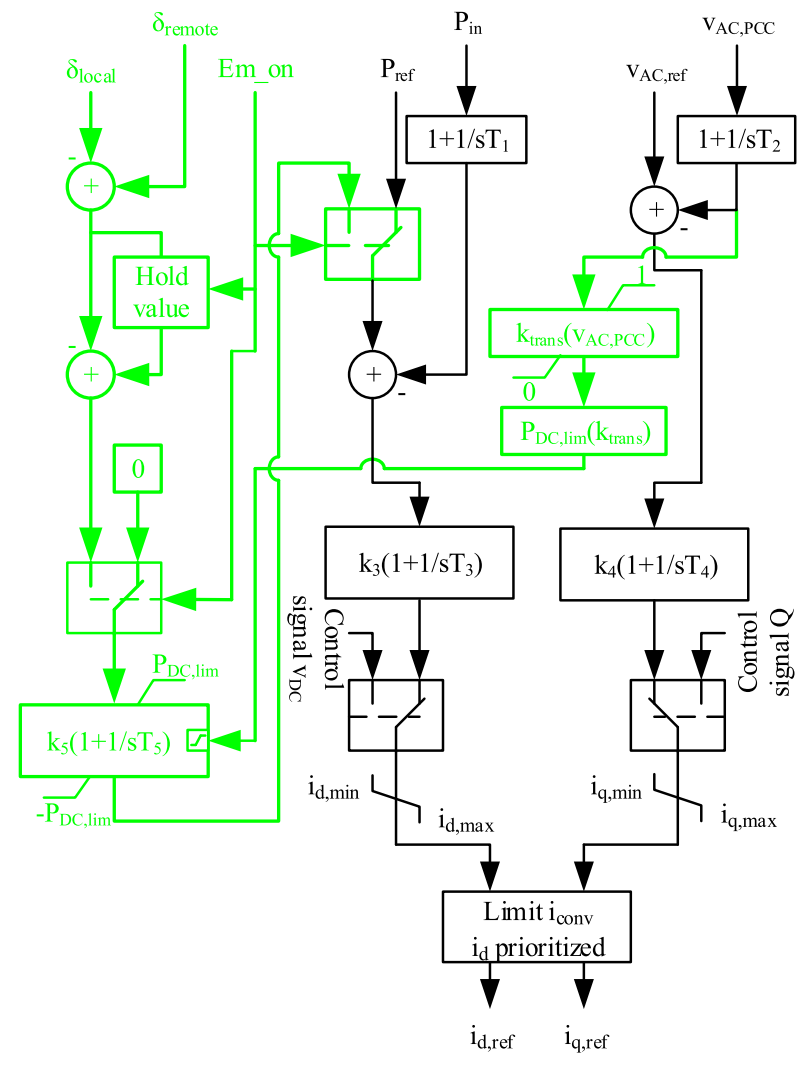

Fig. 3. Outer control loop of the VSC converter. Highlighted parts are the changes to the general control loop. The unchanged parallel paths for $v_{D C}$ - and $Q$-control modes are only implied by their output signals

With the active power limitation given as a function of $k_{\text {trans }}$ the three described operation schemes are combined in one control path.

$$
p_{D C, \text { lim }}=v_{\text {conv, } A C} \cdot i_{\text {conv, } \max } \cdot\left[k_{\text {trans }}+\left(1-k_{\text {trans }}\right) \cdot \sin \left(\delta_{2}-\delta_{1}\right)\right]
$$

The additional $\mathrm{Pl}$ controller for the active power set point and the equations defining the operation schemes are implemented in the outer control loop of the VSC, see Fig. 3. The basic control structure depicted in [9, p. 222] is used as the basic control design. The additional parts are highlighted.

The ECS is activated by the signal Em_on. The activation freezes the output of the hold block and enables the PI-controller in the voltage angle path and switches its output signal as the active power reference. The state variable of the PI-controller is initialized with $P_{\text {ref, }}$ which guarantees a smooth transition between normal operation and the ECS of the converter. This initialization avoids disturbances in the system for unwanted emergency activations. If the $q$-axis current is in $Q$-control mode, the activation of the emergency control switches the control mode to voltage control. Further, the converter feeding active power to the AC network is set to active power control, the converter consuming active power from the $\mathrm{AC}$ network to DC voltage control.

\section{Demonstration in simple grid}

The ECS is demonstrated in the small grid shown in Fig. 4. The simulations are accomplished in the software DigSilent PowerFactory [10].

The demonstration grid represents a transmission corridor connecting a stiff grid with a remote grid area. The main part of the

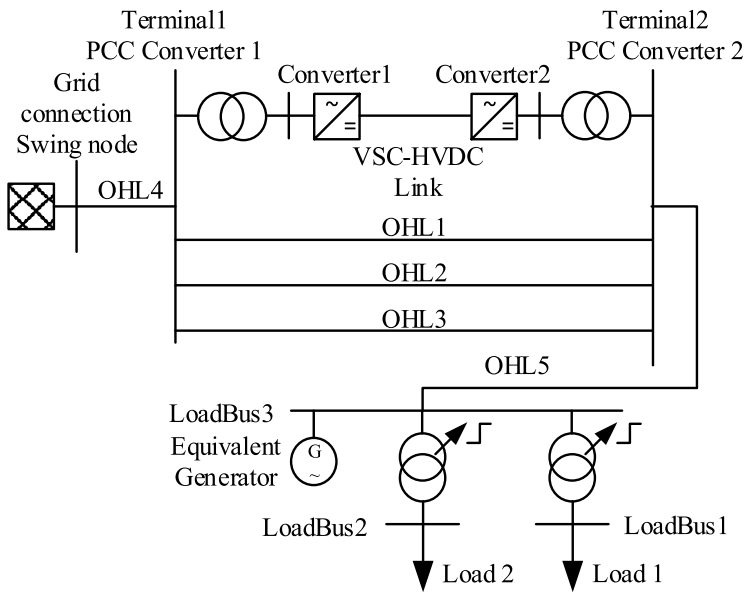

Fig. 4. Demonstration grid. For the derivation of the PV-curves the equivalent generator is disconnected and the on-load tap changer is deactivated.

Table 2. Main network parameters

\begin{tabular}{lllll}
\hline & $\mathrm{X}$ & $\mathrm{R}$ & $\mathrm{C}$ & \\
& $\Omega$ & $\Omega$ & $\mu \mathrm{F}$ & \\
\hline OHL1 -3 & 46.5 & 9 & 1.77 & \\
OHL4 & 2.325 & 0.45 & 1.42 & \\
OHL5 & 3.875 & 0.75 & 2.36 & \\
\hline & $\mathrm{L}$ & $\mathrm{R}$ & $\mathrm{C}$ & \\
& $\mathrm{mH}$ & $\Omega$ & $\mu \mathrm{F}$ & \\
\hline DC Cable & 38.2 & 1.5 & 1.5 & \\
\hline & $\mathrm{S}$ & $\mathrm{Vp}$ & $\mathrm{Vs}$ & $\mathrm{uk}$ \\
& $\mathrm{MVA}$ & $\mathrm{kV}$ & $\mathrm{kV}$ & $\%$ \\
\hline Converter & 700 & 220 & 370 & 11 \\
transformers & & & & \\
Load & 1200 & 220 & 110 & 7.1 \\
transformers & & & & \\
\hline & $\mathrm{S}$ & $\mathrm{VAC}$ & $\mathrm{VDC}$ & $\mathrm{xk}$ \\
& $\mathrm{MVA}$ & $\mathrm{kV}$ & $\mathrm{kV}$ & $\%$ \\
\hline Converter & 600 & 370 & 300 & 15 \\
\hline
\end{tabular}

transmission corridor consists of three $220 \mathrm{kV}$ overhead lines (OHL1 to OHL3) with a length of $150 \mathrm{~km}$ parallel to a VSC-HVDC link with converter rating of $600 \mathrm{MVA}$. The equivalent generator has a rated power of $500 \mathrm{MVA}$ with an inertia constant $\mathrm{H}$ of $7 \mathrm{~s}$. For the demonstration of the ECS the equivalent generator does not contribute to the voltage control of the load bus. The system is loaded by two active power loads, modeled with constant impedance characteristic to introduce voltage dependent behavior. The on-load tap changers of the load transformers enable a simple load recovery for long term voltage stability studies. The main network parameters are given in Table 2.

The parameters defining the active control scheme of the ECS $v_{\text {trans,up }}$ and $v_{\text {trans,low }}$ - are set to 0.95 pu respectively 0.9 pu for the following simulations. 


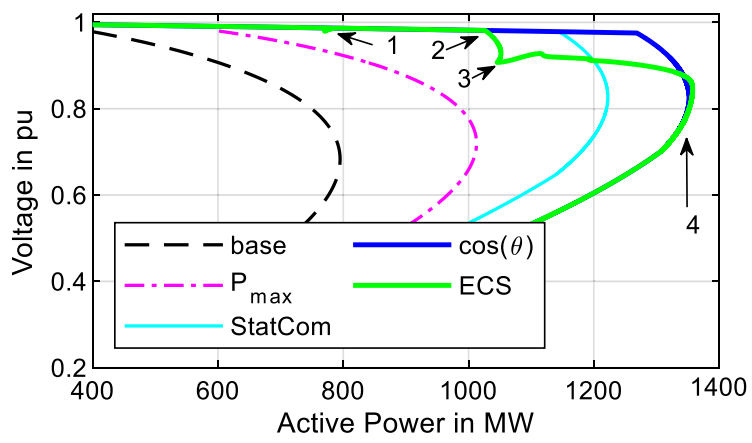

Fig. 5. PV curve of the demonstration network at LoadBus3 for the different converter control strategies and without VSC-HVDC link as base case for reference (Colour figure online)

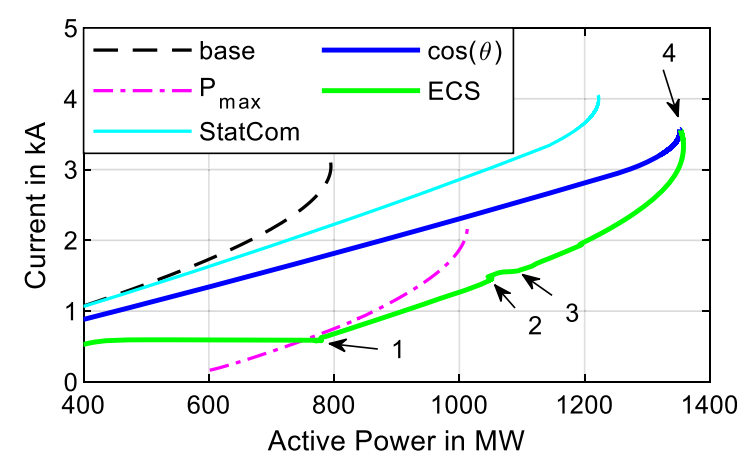

Fig. 6. Total current of the three AC-lines for the different converter control strategies and without VSC-HVDC link as base case for reference (Colour figure online)

The first simulation determines the maximum loading capacity at LoadBus3 by increasing the active power load at this busbar. The load is modeled as a resistive load directly connected to the LoadBus3. The equivalent generator, Load1 and Load2 are disconnected for this simulation. The resulting PV-curves, AC-line currents and the basic converter behavior for ECS are shown in Fig. 5 to Fig. 7. The results confirm qualitatively the steady state simulation of Sect. 2 . The ECS reaches the same maximum loadability as the $\cos (\theta)$-control, but the loading of the parallel AC-lines is lower. The higher loading of the AC-lines of the ECS compared to the $P_{\max }$ control at lower load powers depend on the initial angle difference at activation of the ECS. For the simulation of the PV-curves, the initial load is 400 MW and active power of the VSC-HVDC link before activation of the ECS is $200 \mathrm{MW}$.

In Figs. 5, 6, 7 four moments associated with special critical control actions are marked for the ECS. At (1), Converter1 - controlling the DC voltage of the VSC-HVDC link - reaches its maximum current of $1.2 \mathrm{pu}$ and $v_{D C}$ drops. Converter 2 reacts by limiting its $d$-axis current to stabilize $v_{D C}$. At (2), Converter2 reaches its current limit too. Since it is still operated in the $P_{\text {prior }}$ scheme, the q-axis current is reduced with rising $d$-axis current. At (3, the voltage at the terminal of Converter2 falls below $v_{\text {trans,up }}$ and the transition phase begins. With decreasing d-axis current, the $D C$ voltage recovers and the $D C$ voltage control is handled again by Converter1. At (4), the transition variable $k_{\text {trans }}$ becomes 0 and the ECS behaves identically to $\cos (\theta)$-control. Note that the $d$ - and $q$-axis current are used instead of active and reactive in Fig. 7 .

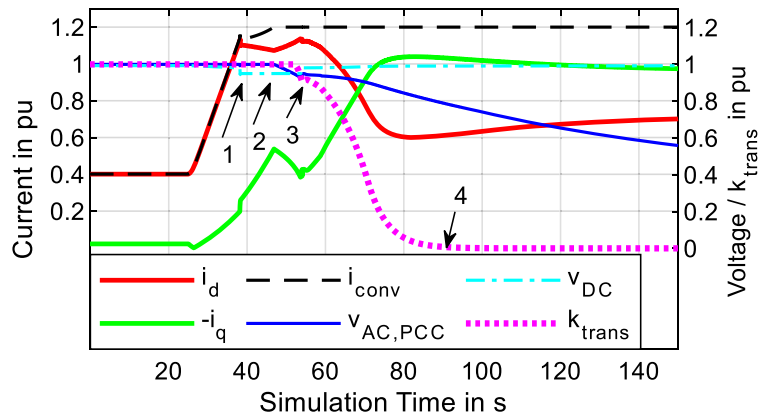

Fig. 7. $d$-axis, $q$-axis, converter current, $k$ trans, DC- and AC-voltage of the PCC of Converter2 with active ECS during the simulation determining the PV-curve (Colour figure online)

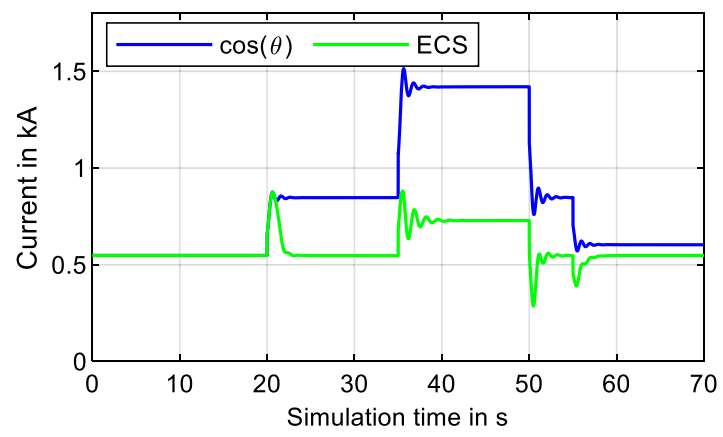

Fig. 8. Line current in OHL1 for disconnection and reconnection of the parallel lines $\mathrm{OHL} 2$ and $\mathrm{OHL} 3$ (Colour figure online)

The following simulations of line tripping and generation loss are only performed for the $\cos (\theta)$-control and the ECS. For these simulations, the equivalent generator supplies active power without voltage control and the on-load tap changer of the load transformers are activated. The loads Load1 and Load2 act as simple impedance loads with unity power factor. The deactivated voltage control of the equivalent generator was chosen to focus on the differences between the compared control strategies of the VSC-HVDC link.

Figure 8 shows the line current in OHL1 for a line tripping sequence. The equivalent generator operates at $250 \mathrm{MW}$ and the loads are set to $650 \mathrm{MW}$ and $400 \mathrm{MW}$ respectively. The VSC-HVDC is initially loaded with $200 \mathrm{MW}$, leaving $600 \mathrm{MW}$ for the parallel AC system. Voltage control is done on both HVDC-terminals within the available converter capacity. At $t=20 \mathrm{~s} \mathrm{OHL2} \mathrm{trips} \mathrm{and} \mathrm{at} t=21 \mathrm{~s}$ either the $\cos (\theta)$-control or the ECS is activated as a counter measurement to the line tripping. At $t=35 \mathrm{~s} \mathrm{OHL} 3$ trips as well. The lines are reconnected at $t=50 \mathrm{~s}$ and $t=55 \mathrm{~s}$ respectively.

The results for $\cos (\theta)$-control indicate that the current in the remaining line $\mathrm{OHL} 1$ exceeds the rated current of $1.2 \mathrm{kA}$ after the second line being disconnected. This would force OHL1 to trip resulting in a network split. A similar sequence of events caused [1].

Using the ECS instead, the current limit of the remaining line OHL1 is not violated. The ECS tries to control the active and reactive power at Converter2 in such a way that the remaining $A C$ lines keep their pre-fault loading. However, the rise in the AC line current after the tripping of $\mathrm{OHL} 3$ is caused by the current limitation of Converter1. After the end of the disturbance, the AC system reaches its initial state again.

To test the reaction of $\cos (\theta)$-control and the ECS in case of loss of generation, the loads Load1 and Load2 are set to $650 \mathrm{MW}$ and the 


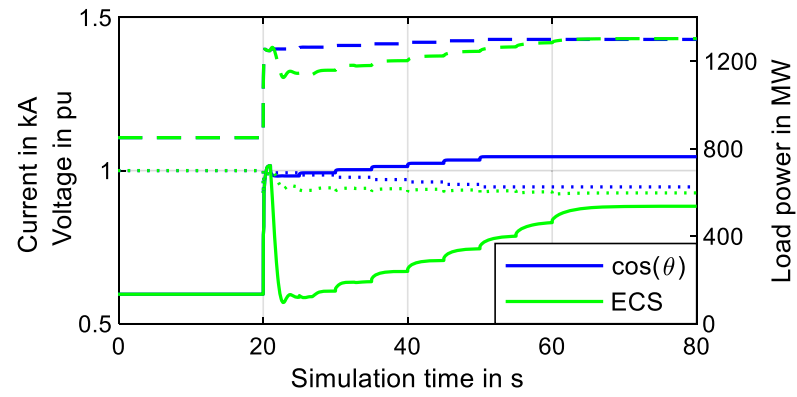

Fig. 9. Line current in OHL1 for disconnection and reconnection of the parallel lines $\mathrm{OHL} 2$ and $\mathrm{OHL} 3$. The continuous lines are the line currents in OHL1, the dashed lines are the load power and the pointed line is the voltage at Terminal2 (Colour figure online)

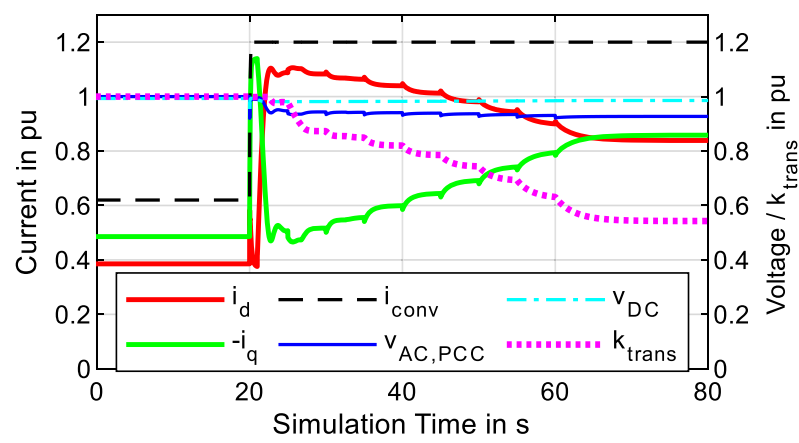

Fig. 10. $d$-axis, $q$-axis, converter current, $\boldsymbol{k}_{\text {trans, }} \mathrm{DC}$ - and AC-voltage of the PCC of Converter2 with active ECS for the simulation of loss of generation (Colour figure online)

equivalent generator feeds $450 \mathrm{MW}$ into the system. The combined load at LoadBus3 of $1300 \mathrm{MW}$ is close to the maximum loading capacity - $1352 \mathrm{MW}$ for $\cos (\theta)$-control and $1358 \mathrm{MW}$ for the ECS respectively. The equivalent generator is disconnected at $t=20 \mathrm{~s}$ and as reaction either $\cos (\theta)$-control or ECS is activated at $t=21 \mathrm{~s}$. As shown in Fig. 9, both control strategies reach a stable operation point after the load recovers. However, the ECS leads to less loading of the $A C$ lines at a slightly lower terminal voltage.

Figure 10 shows the dynamic behavior of some internal control signals of the ECS. The $d$-axis current rises with the activation of the $\mathrm{ECS}$ at $t=21 \mathrm{~s}$, leading to decreasing voltage at the PCC due to the reduced capacity used for voltage control. With the recovery of the load by the on-load tap changer, the rising currents in the AC lines lead to a further decrease in the voltage at the PCC. According to the equations (3) and (4), the share of the converter capacity used for voltage control rises and the voltage at the PCC and LoadBus3 stabilizes.

\section{Conclusion and discussion}

An advanced emergency control strategy for embedded VSC-HVDC links in terms of long-term voltage stability and cascading effects is investigated in this paper. The conducted simulations aim to demonstrate its advantages and usability in improving the voltage stability and support for the parallel AC system. The discussed scenarios show that the ECS improves the system reaction to disturbances. Compared to existing control strategies usable for emergency con- trol, it performs better in terms of unloading of the parallel ACnetwork and at least at the same level in terms of long term voltage stability. The transferrable power of the test system is increased when the embedded VSC-HVDC link rated 600 MVA is set into operation by $557 \mathrm{MW}$ with $\cos (\theta)$-control respectively $563 \mathrm{MW}$ with the ECS. A further advantage of the ECS is, that it does not disturb the system if activated accidentally. The shown simulation results represent only a part of the conducted simulations and are selected as representative cases.

In summary, embedded VSC-HVDC links with a proper control are able to significantly improve system resilience to disturbances as were mentioned in the introduction [1-4].

The next steps are to implement the ECS in more complex networks, such as the Nordic32 test system. Further, its capability to react to short term voltage stability problems, if operated at the operational limits of the VSC-HVDC link have to be investigated.

Funding Note Open access funding provided by Graz University of Technology.

Publisher's Note Springer Nature remains neutral with regard to jurisdictional claims in published maps and institutional affiliations.

Open Access Dieser Artikel wird unter der Creative Commons Namensnennung 4.0 International Lizenz veröffentlicht, welche die Nutzung, Vervielfältigung, Bearbeitung, Verbreitung und Wiedergabe in jeglichem Medium und Format erlaubt, sofern Sie den/die ursprünglichen Autor(en) und die Quelle ordnungsgemäß nennen, einen Link zur Creative Commons Lizenz beifügen und angeben, ob Änderungen vorgenommen wurden. Die in diesem Artikel enthaltenen Bilder und sonstiges Drittmaterial unterliegen ebenfalls der genannten Creative Commons Lizenz, sofern sich aus der Abbildungslegende nichts anderes ergibt. Sofern das betreffende Material nicht unter der genannten Creative Commons Lizenz steht und die betreffende Handlung nicht nach gesetzlichen Vorschriften erlaubt ist, ist für die oben aufgeführten Weiterverwendungen des Materials die Einwilligung des jeweiligen Rechteinhabers einzuholen. Weitere Details zur Lizenz entnehmen Sie bitte der Lizenzinformation auf http://creativecommons.org/licenses/by/4.0/deed.de.

\section{References}

1. UCTE (2007): Final report - system disturbance on 4 November 2006

2. UCTE (2003): Final report of the Investigation Committee on the 28 September 2003 blackout in Italy.

3. Larsson, S., Danell, A. (2006): The black-out in southern Sweden and eastern Denmark, September 23, 2003. In 2006 IEEE PES power systems conference and exposition (pp. 309-313).

4. Andersson, G., et al. (2005): Causes of the 2003 major grid blackouts in North America and Europe, and recommended means to improve system dynamic performance. IEEE Trans. Power Syst., 20(4), 1922-1928.

5. Kundur, P. (1994): Power system stability and control. Toronto: McGraw-Hil.

6. Cholley, P., et al. (2001): In System protection schemes in power networks, Paris

7. Tirtashi, M. R. S., Svensson, J., Samuelsson, O. (2017): VSC-HVDC application to improve the long-term voltage stability. In 2017 IEEE Manchester PowerTech, Powertech 2017.

8. Johansson, S., Asplund, G., Jansson, E., Rudervall, R. (2004): Power system stability benefits with VSC DC-transmission systems. In Cigré Conference Session 2004 (pp. 1-8)

9. Jovcic, D., Ahmed, K. (2015): High voltage direct current transmission. 1st ed. Chichester: Wiley.

10. DigSilent (2019): PowerFactory 2019, SP2 - Academic License. [Online]. http://www. digsilent.de/. 


\section{Authors}
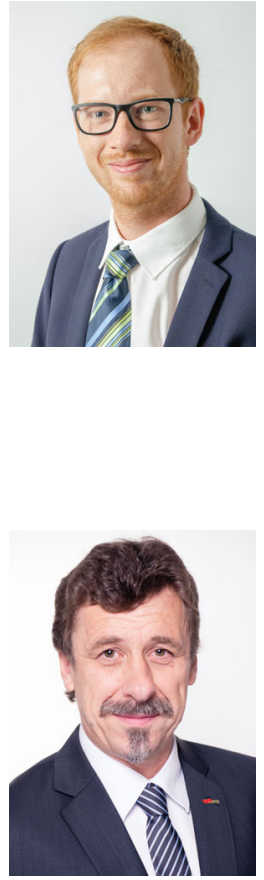

\section{Stefan Polster}

received the master degree in electrical engineering, in 2016, from Graz University of Technology, Austria, where he is currently working toward his Ph.D. degree. His research mainly deals with power system dynamics and load flow calculation. In 2017 he became a recipient of a DOC Fellowship of the Austrian Academy of Sciences at the Institute of Electrical Power Systems, Graz University of Technology.

\section{Herwig Renner}

holds a position as associate professor at Graz University of Technology. His research is in the field of power system planning and operation with special focus on transmission system dynamics and industrial power quality.

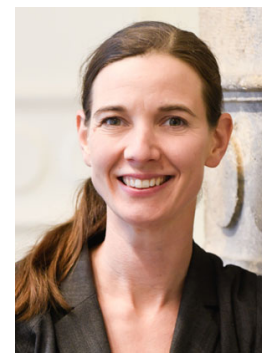

\section{Katrin Friedl}

was born in Scheibbs, Austria, in 1981. After completing her diploma in electrical engineering at the Vienna University of Technology in 2005, she completed her doctorate in 2012 at the Graz University of Technology. Afterwards she worked with the TSO Austrian Power Grid AG focusing on electromagnetic fields and planning of the networks. Since 2019, she has been working at the Institute for Electrical Power Systems, Graz University of Technology. Her research focuses on the calculation and assessment of low-frequency magnetic and electrical fields, electromagnetic interference and grounding of power systems.

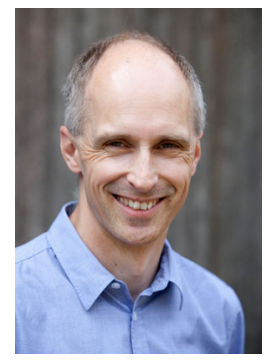

\section{Olof Samuelsson}

is professor of Electric Power Systems at the division of Industrial Electrical Engineering and Automation, Lund University, where he also received his M.Sc. in 1989 and Ph.D. in 1997. His research covers transmission issues such as dynamics (damping, inertia), stability and large disturbances (including geomagnetically induced currents), as well as distribution issues such as microgrids, integration of distributed generation and resilience to large disturbances. 